\title{
What should be evaluated from a manager's perspective? Developing a salient protected area effectiveness evaluation system for managers and scientists in Spain
}

\author{
D. Rodríguez-Rodríguez, J. Martínez-Vega
}

Keywords: $\quad$ Protected area, Effectiveness, Assessment system, Network manager, Scientist, SIAPA.

\begin{abstract}
The System for the Integrated Assessment of Protected Areas (SIAPA) was developed as a tool to improve our knowledge on the status and trends of protected biodiversity. In order to increase SIAPA's salience and use, representatives of the main managerial and scientific protected area (PA) institutions of Spain were surveyed using a structured questionnaire. PA network managers and scientists showed a high degree of consistency in rating the most important SIAPA indicators: 'Appropriateness of protection legislation', 'Degree of fulfilment of management objectives' and 'Effectiveness of public participation bodies', respectively. However, PA managers perceived the 'State of conservation' as the most determinant factor to ascertain overall PA effectiveness whereas for scientists 'Management' was the most important factor. Most managers and one scientist suggested including the indicator 'Change in extent of focal habitats' in the SIAPA and comparing management effects inside and outside PAs. The methods and results of this study intend to streamline and standardise PA evaluation efforts in Spain and guide future developments of PA evaluation systems elsewhereimportance of future LULC scenarios when planning fire prevention measures.
\end{abstract}

\section{Introduction}

Protected areas are at the forefront of global biodiversity conservation efforts (Chape et al., 2008). As a result of the importance given to assessing PAs' conservation performance, a framework for evaluating management effectiveness was developed by the International Union for the Conservation of Nature (IUCN; Hockings et al., 2000) and a large number of PA evaluation systems and tools has been developed in Europe (Nolte et al., 2010) and worldwide (Leverington et al., 2010a). In 2010, the Convention on Biological Diversity (CBD) set the target to evaluate at least $60 \%$ of the world's protected area by 2015 (CBD, 2010a). Additionally, the CBD's Aichi Target 11 states the need to 'conserve areas of particular importance for biodiversity through systems of PAs that are effectively and equitably managed, ecologically representative and well-connected' (CBD, 2010b). However to date just $29 \%$ of nation-ally designated PAs have been evaluated on their management effectiveness globally (Coad et al., 2013) and many of these evaluations rely on the subjective judgement of PA managers through tools like the Rapid Assessment and Prioritization of Protected Areas Management (Ervin, 2003) or the Management Effectiveness Tracking Tool (Stolton et al., 2007).
The System for the Integrated Assessment of Protected Areas(SIAPA; Rodríguez-Rodríguez and Martínez-Vega, 2012) was originally developed to help to fill the gap in PA effectiveness evaluation in Spain (Múgica and Gómez-Limón, 2002) and, more immediately, in the Autonomous Region of Madrid (ARM) given the important pressures jeopardising biodiversity conservation in the region (RodríguezRodríguez, 2008). The development of the SIAPA was scientifically-led with a relatively wide input from a range of stakeholders (Rodríguez-Rodríguez and Martínez-Vega, 2012), although PA managers' participation was limited to the PA managers of the ARM, which may have compromised its representation and salience at the Spanish scale (Rodríguez-Rodríguez et al.,2015). Two versions of the original SIAPA were developed: a Complete Model made of 43 indicators, and a Simplified Model made of the 28 most highly rated indicators of the Complete Model, aimed at increasing salience and implementation efficiency (Rodríguez-Rodríguez and Martínez-Vega, 2012). The SIAPA was first tested on the 10 PAs of the ARM (Rodríguez-Rodríguez and Martínez-Vega, 2013a). However, limited interest in the tool shown by its intended users in the ARM and the rest of Spain (RodríguezRodríguez et al., 2015), prompted us to adapt the SIAPA to better meet the needs of the country's PA managers and network managers in order to promote the use of objective, systematic PA evaluations in Spain. These kinds 
of evaluations are even more relevant in a country with unusually high levels of biodiversity in the European context (CBD, 2014): the Spanish territory spans across 4 biogeographical regions: Mediterranean, Alpine, Atlantic and Macaronesian (EEA, 2006); one-hundred and eighteen habitats in the Annex 1 of the Habitats Directive; 263 species in the Annex 2; and 125 species in the Annex 1 of the Birds Directive occur on Spanish land and waters (MAGRAMA, 2015); Spain is the country that contributes most to the Natura 2000 net-work in terms of absolute area with 1448 Sites of Community Importance and 598 Special Protection Areas which together cover $27.27 \%$ of the country's terrestrial and marine area (MAGRAMA, 2015).

With the aim of presenting the SIAPA to potential end users, improving it, and adapting it to users' needs, we organised a national workshop in Madrid. The workshop's main aim was to assess the possibility of using the improved version of the SIAPA resulting from the workshop as a common, standardised PA evaluation system in Spain. This paper reflects some of the results from that workshop. The objectives of this study were manifold: (1) to identify the indicators and indexes of the SIAPA considered most important for PA network managers and scientists in Spain for assessing PA effectiveness in order to increase the SIAPA's salience among end-users; (2) to validate the greater salience of the Simplified Model of the SIAPA versus the Complete Model among Spanish PA network managers and scientists; (3) to assess the consistency in the ratings of the SIAPA indicators and indexes by PA network managers and scientists attending the workshop and the original SIAPA stakeholders, to estimate the national representation of the SIAPA; (4) to determine the consistency in the ratings of the indicators and indexes of the SIAPA between PA network managers and the PA network manager of the ARM, as a possible indication of the ARM's environmental specificity with regard to the rest of the country, as suggested during the workshop; and (5) to discuss possible improvements to the SIAPA and PA evaluation systems in general so that conservation outcomes can be more accurately attributed to management actions.

\section{Materials and methods}

\subsection{Workshop development questionnaire and administration}

We organised a national workshop on PA effectiveness evaluation through a collaboration agreement between the BBVA Foundation and the Spanish National Research Council in May 2013 (Europa Press, 2013). Invitees included over 50 representatives from national, regional and local PA networks, research institutions, environmental NGOs, local government organisations, environmental foundations and the International Union for the Conservation of Nature (IUCN; IUCN-World Commission on Protected Areas and Spanish IUCN Committee). Even though participation in the workshop was voluntary, 26 organisations attended. They are shown in appendix A in the supplementary material. Eight weeks before the workshop, every invitee was sent the complete electronic version of the monograph explaining the methodological development of the SIAPA in Spanish (Rodríguez-Rodríguez and Martínez-Vega, 2013b) to allow them to familiarise with it in advance.

In the workshop, we presented the methodology underpinning the SIAPA (Rodríguez-Rodríguez and Martínez-Vega, 2012) and circulated a structured questionnaire with closed ended questions (appendix B in the supplementary material). Participants were asked to rate each indicator and index of the SIAPA on a Likerttype scale from 1 to 5 points where $1=$ not important; $2=$ slightly important; $3=$ moderately important; $4=$ rather important; and $5=$ very important, according to their importance for defining the partial indexes (state of conservation; planning; management; social and economic context; social perception and valuation; and threats to conservation) or the global effectiveness index where they were included, respectively (Rodríguez-Rodríguez and Martínez-Vega,2012). Optional open-ended questions gave the participants the possibility of suggesting new indicators or indexes that were not currently included in the SIAPA and of making comments.

Here, we analysed the responses by the two main stakeholder groups attending the workshop as potential end users of the SIAPA:(1) PA network managers, represented by 11 of the 17 regional PA network manager institutions of the country and the two representatives of the national institutions coordinating management, monitoring and reporting activities in the Spanish network of national parks (the National Parks Autonomous Body; OAPN) and Natura 2000 sites (Ministry of Environment); and (2) scientists, including one representative from three of the main research institutions working on PAs in Spain: EUROPARC-Spain, the Spanish Observatory for Sustainability (OSE), and a Spanish representative of the IUCN-World Commission on Protected Areas. The sample of managers present at the workshop managed 1026 PAs, mostly terrestrial. These PAs represent 59.9\% of Spain's nationally designated PAs and $82.1 \%$ of the terrestrial area protected. They span across three biogeographic regions: Mediterranean, Alpine and EuroSiberian (EEA, 2006).

We compared the ratings of these two priority groups attend-ing the workshop (PA network managers and scientists) with the ratings of two other groups of interest: the original SIAPA stake-holders and the PA network manager of the ARM, to elicit possible representation issues with the first version of the SIAPA (RodríguezRodríguez et al., 2015). Original SIAPA stakeholders included: the PA network manager of the ARM, the OSE 
Table 1

Ranking of the SIAPA indicators by PA network managers (R.mSIAPA; $\mathrm{n}=12$ ) and scientists (R.sSIAPA; $\mathrm{n}=3$ ) ordered according to their increasing coefficients of variation by

PA network managers (CV.mSIAPA), and differences in rankings (Rank.Dif = R.sSIAPA-R.mSIAPA).

\begin{tabular}{|c|c|c|c|c|}
\hline & CV.mSIAPA & R.mSIAPA & R.sSIAPA & Rank Dif \\
\hline Appropriateness of protection legislation & 8.40 & 1 & 1 & 0 \\
\hline Degree of fulfilment of management objectives & 9.52 & 2 & 2 & 0 \\
\hline Effectiveness of public participation bodies & 12.61 & 3 & 7 & 4 \\
\hline Population trends of endangered species or subspecies & 13.96 & 4 & 2 & -2 \\
\hline Monitoring & 14.59 & 5 & 4 & -1 \\
\hline Fragmentation & 14.63 & 6 & 3 & -3 \\
\hline Local population density & 15.00 & 7 & 9 & 2 \\
\hline Degree of knowledge on the protected area by local populations & 15.14 & 8 & 1 & -7 \\
\hline Existence of updated management documents & 15.43 & 9 & 3 & -6 \\
\hline Landscape impact & 15.79 & 10 & 8 & -2 \\
\hline Personal importance & 15.79 & 10 & 5 & -5 \\
\hline Surface water quality & 16.37 & 11 & 6 & -5 \\
\hline Existence of environmental education and volunteering activities & 17.76 & 12 & 17 & 5 \\
\hline Existence of sufficient management staff & 17.95 & 13 & 3 & -10 \\
\hline Presence of alien invasive species & 17.97 & 14 & 4 & -10 \\
\hline Zoning & 18.78 & 15 & 16 & 1 \\
\hline Existence of updated natural resources planning documents & 20.04 & 16 & 7 & -9 \\
\hline Existence of updated documents on public use & 21.23 & 17 & 5 & -12 \\
\hline Evolution of the feature(s) for which the protected area was designated & 22.71 & 18 & 7 & -11 \\
\hline Accessibility & 22.79 & 19 & 5 & -14 \\
\hline Land use changes & 23.84 & 20 & 2 & -18 \\
\hline Area affected by fires & 24.05 & 21 & 3 & -18 \\
\hline Economic valuation of the protected area & 24.27 & 22 & 19 & -3 \\
\hline Easiness to identify the protected area & 24.28 & 23 & 20 & -3 \\
\hline Isolation & 24.40 & 24 & 12 & -12 \\
\hline Activities performed by visitors & 25.44 & 25 & 11 & -14 \\
\hline Public use infrastructure & 26.36 & 26 & 22 & -4 \\
\hline Investment in the protected area & 26.65 & 27 & 10 & -17 \\
\hline Presence of solid waste & 27.19 & 28 & 13 & -15 \\
\hline Climate change & 27.64 & 29 & 11 & -18 \\
\hline Degree of characterisation of the protected area & 28.22 & 30 & 7 & -23 \\
\hline Health of vegetation & 28.57 & 31 & 15 & -16 \\
\hline Land ownership & 28.63 & 32 & 6 & -26 \\
\hline Perception of the conservation state & 31.06 & 33 & 5 & -28 \\
\hline Number of visitors & 32.19 & 34 & 12 & -22 \\
\hline Production and distribution of an annual report on activities and outcome & 33.36 & 35 & 16 & -19 \\
\hline Main economic activities in the protected area & 34.76 & 36 & 18 & -18 \\
\hline Existence of updated documents on social and economic development & 36.93 & 37 & 5 & -32 \\
\hline $\begin{array}{l}\text { Number of municipalities in the protected area } \\
\text { Area provided for the protected area by municipalities with local Agenda }\end{array}$ & 39.80 & 38 & 22 & -16 \\
\hline 21 & 40.00 & 39 & 22 & -17 \\
\hline Air quality & 41.39 & 40 & 14 & -26 \\
\hline Sanctioning procedures & 44.20 & 41 & 22 & -19 \\
\hline Evolution of the area designated as protected & 48.37 & 42 & 21 & -21 \\
\hline
\end{tabular}


and the National Ministry of Environment for rating indicators; and, additionally, the Catalan Institute of Natural History, the Department of Ecology of the Faculty of Biology of the Complutense University of Madrid and the NGO Ecologistas en Acción for rating the 6 SIAPA partial indexes.

\subsection{Indicator prioritisation}

We compared the ratings given to the SIAPA indicators by PA network managers and scientists. The 43 indicators (n $=12$ man-agers) and 6 partial indexes $(\mathrm{n}=11$ managers $)$ in the Complete Model of the SIAPA were ranked according to the decreasing degree of agreement on their importance by the group of PA network managers using the increasing coefficient of variation $(\mathrm{CV})$ of their responses. Thus, indicators with the highest means and lowest standard deviations (resulting in lowest $\mathrm{CVs}$ ) were ranked as the most important for the respondents. The CV is considered a robust estimate of inter-observer precision and is widely used for that purpose (Euser et al., 2008), even in non-normal distributions of data (Bonett, 2006). For the group of scientists, given the low number of cases $(n=3)$ that resulted in a number of SIAPA indicators having a $\mathrm{CV}=0$ due to the unanimity of responses, we estimated the degree of agreement by ranking the indicators using three tiered criteria: (a) decreasing means; (b) increasing CVs; and (c) decreasing number of responses for each indicator. The difference in order in which each indicator was ranked by both groups according to their decreasing degree of consensus (i.e. indicator ranking by PA network managers - indicator ranking by scientists) was then used as a second metric to prioritise indicator selection jointly. A maximal difference in groups' rankings of 4 units was used as an indicator selection threshold (coincidence) among the top rated indicators by PA network managers. Calculations were made using Microsoft Excel.

\subsection{Comparison of the salience of both models of the original SIAPA}

The means and standard deviations of the indicator ratings of the Complete and Simplified models of the SIAPA (Rodríguez-Rodríguez and Martínez-Vega, 2012) by PA network managers and scientists were computed in Microsoft Excel, as an estimation of the relevance of each model to assess PA effectiveness in Spain by both groups in order to validate previous assumptions (RodríguezRodríguez and Martínez-Vega, 2012).

\subsection{Degree of consistency of stakeholders' ratings of SIAPA indicators and indexes}

We calculated the mean ratings of each of the 43 SIAPA indicators and 6 partial indexes by four different groups: PA network managers ( $\mathrm{n}=12$ for indicators and $\mathrm{n}=11$ for indexes); scientists $(\mathrm{n}=3)$; original SIAPA stakeholders ( $\mathrm{n}$ $=3$ for indicators and $\mathrm{n}=6$ for indexes; in the original 0 to 3-point scale for indicators, as shown in Rodríguez-
Rodríguez and Martínez-Vega (2012); and the PA network manager of the ARM ( $n=1$; in the original 0 to3-point scale for indicators). We tested the normality of the variables using the Shapiro-Wilk test and the possibility of operating with transformed variables to achieve normality. Spearman's correlation analyses were then performed to ascertain the degree of inter-observer agreement in the ratings of the SIAPA indicators and indexes between groups. Calculations were made using SPSS v.21for a significance level of 0.05 .

\section{Results}

\subsection{Indicator prioritisation}

There were 7 SIAPA priority indicators highly rated by both groups, with a maximum difference in rankings of \pm 4 units. Other SIAPA indicators did not show such high degree of agreement between groups or, when they did (e.g. 'Landscape impact'; 'Zoning'), they were noticeably less rated by PA network managers. The complete ranking of the SIAPA indicators by PA network managers and scientists is shown in Table 1

\subsection{Open responses by managers and scientists}

\subsubsection{Additional indicators}

Managers suggested including 30 new indicators (appendix $\mathrm{C}$ in the supplementary material), although the only ones with a high or moderately high degree of agreement (according to their number of mentions) were: 'Change in extent of focal habitats' (mentioned by 8 of the 11 managers), 'Monitoring of economic activities dependent of PAs' and 'Trend of traditional economic activities that favour the conservation of species and habitats' (3 mentions each). These new indicators were also mentioned by scientists. Scientists pro-posed 12 new indicators to be added to the SIAPA although there was low degree of agreement as all of them were proposed by just one participant.

\subsubsection{Integration of indicators in indexes}

Some participants suggested including some of the indicators under different SIAPA indexes, although the degree of agreement was low as each change was only suggested by one participant

\subsection{Comparison of the salience of both models of the original SIAPA}

PA network managers rated both models of the SIAPA slightly higher than scientists and both groups rated the Simplified Model slightly higher than the Complete 
Model, although in neither case were the differences statistically significant (Fig. 1).

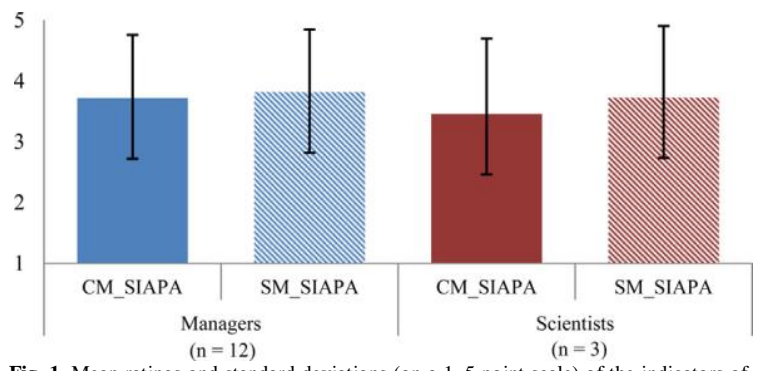

Fig. 1. Mean wand and standard deviations (on a 1-5 point scale) of the indicators of Simplified Model) by PA network managers and scientists

\subsection{Degree of consistency in the ratings of SIAPA indicators and indexes}

For indicators, significant correlations were found between PA network managers and scientists, and between scientists and original SIAPA stakeholders. For indexes, significant correlation (although on the verge of significance level) was found between PA network managers and the PA network manager of the ARM. The results of the statistical correlations in the ratings of SIAPA indicators and indexes between groups are shown in Table 2.

Table 2

Between-group, Spearman's correlations of the ratings of the SIAPA indicators and partial indexes.

\begin{tabular}{ccc} 
Groups & Indicators' ratings & Indexes ratings \\
\hline mSIAPA and SSIAPA & $\mathrm{r}(41)=0.689^{* *} ; \mathrm{p}=0.000$ & $\mathrm{r}(4)=0.721 ; \mathrm{p}=0.106$
\end{tabular}

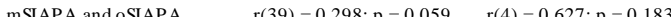
STAPA $\begin{array}{lll}\text { mSIAPA and armSIAPA } & \mathrm{r}(39)=0.159 ; \mathrm{p}=0.320 & \mathrm{r}(4)=0.814 * ; \mathrm{p}=0.049 \\ \text { mSIAPA: PA net work managers }(\mathrm{n}=12 \text { for indicators and } \mathrm{n}=11 \text { for indexes); oSIAPA: }\end{array}$ original SIAPA stakeholders ( $\mathrm{n}=3$ for indicators and $\mathrm{n}=6$ for indexes); sSIAPA: scientists $(\mathrm{n}=3)$; armSIAPA: PA network manager of the Autonomous Region of Madrid $(\mathrm{n}=1)$

Regarding ratings of the SIAPA partial indexes, PA network man-agers and the PA network manager of the ARM rated 'State of conservation' the highest, where as scientists rated 'Management' the highest. The mean values given to the SIAPA indexes by the four groups are shown in Table 3.

\section{Discussion}

\subsection{Indicator prioritisation}

PA network managers and scientists highlighted 'Appropriateness of protection legislation', 'Degree of fulfilment of management objectives' and 'Effectiveness of public participation bodies' as the most important indicators to assess the effectiveness of a PA. These indicators, or their proxies, are considered 'headline indicators' for assessing PA management effectiveness globally (Leveringtonet al., 2010b) and have been included in over 60\%, 20\% and 80\% of European evaluations, respectively (Nolte et al., 2010). In other parts of the world, it has been suggested that PA managers prioritise information on species and ecosystem occurrence, threats and management strategies, especially related to threatened bio-diversity (Cook et al., 2012). Surprisingly, here 'Population trends of endangered species or subspecies', which should be the primary aim of any PA (Dudley, 2008), was only ranked in the fourth place by responding PA network managers. On the other hand, the new indicator 'Change in extent of focal habitats' was suggested for inclusion.

There was a moderately high degree of agreement between managers and scientists regarding the most highly ranked indicators, although managers tended to rank most indicators lower than scientists. Such consistency in the responses of scientists and managers should facilitate the implementation of a common, agreed and salient assessment system in Spain made of a small number of indicators including, at least, the 7 most highly ranked indicators by managers and scientists plus the suggested, highly agreed indicator 'Change in extent of focal habitats'. The first 7 priority indicator shave already been developed (Rodríguez-Rodríguez and Martínez-Vega, 2012) and trialled (Rodríguez-Rodríguez and MartínezVega,2013a). Additionally, all the 7 priority indicators are included, as such or as proxies, in the regular OAPN monitoring programme which should further facilitate standardisation of PA monitoring in Spain, although valuation thresholds have not been established by the OAPN and some data compilation protocols (e.g. for fragmentation) seem not to have been developed yet (MAGRAMA, 2012). As a result, the 'synthetic' system proposed here could greatly enhance cost-effectiveness in a context of increasing budgetary efficiency (Múgica et al.,2012) as well as increase analytical power of existing systems by introducing national valuation thresholds or adapting existing ones. The addition of the suggested priority indicator 'Change in extent of focal habitats' would complement the system and make it fit for evaluating all types of terrestrial PAs in Spain and, possibly, PAs in other European Union countries, including Natura 2000 sites, which require periodic monitoring of species and habitats of community interest (EU, 1992). This synthetic standardised system of 8 indicators could then be complemented with few sitespecific indicators according to local contexts and conditions. For this combined approach to be fully participative, legitimate and knowledge-based, the integration of interests, expectations and insights of a range of different stakeholders including local residents would be needed (Reed, 2008).

PA network managers and scientists also agreed in the ranking of the least important indicators: 'Evolution of the area designated as protected', 'Sanctioning procedures' and 'Air quality'. Given the importance of enforcement for the ecological effectiveness of PAs (Edgar et al., 2014; Leverington et al., 2010b), it was surprising the low ratings of the only SIAPA indicator of enforcement 
effectiveness: 'Sanctioning procedures'. It was also noteworthy that other lowly rated indicators by managers, such as 'Land ownership' or 'Perception of the conservation state' are regularly included in the performance reports of the Spanish net-work of national parks (MAGRAMA, 2012). This might be the result of the scientific-led methodology followed in those reports. Similarly, some other ratings by PA network managers in Spain contrast with available European evidence and common PA managers' com-plaints (RodríguezRodríguez et al., 2015). For example, 'Evolution of investment in the PA' was ranked lowly in spite of serious funding constraints reported for PAs in Europe (Nolte et al., 2010) and globally (Leverington et al., 2010a). This result is even more surprising in the current context of prolonged economic crisis affecting Spain (RodríguezRodríguez, 2012b) that has resulted in notable staff and budget cuts in nature conservation in recent years (Múgicaet al., 2012). Likewise, Spanish PA network managers rated 'Activities performed by visitors' lowly in contrast with numerous studies that highlight the relevance of recreational activities as important threats to PAs globally (Chape et al., 2008; Leverington et al., 2010a), in Europe (Nolte et al., 2010) and in some parts of Spain (Mallarach,2008; Rodríguez-Rodríguez, 2008).

The high degree of consistency in the rankings of the SIAPA indicators between PA network managers and scientists in Spain may be explained to a degree by the long-lasting collaboration between some scientific and managerial institutions attending the workshop: EUROPARC-Spain has been collating information on the PAs of Spain with input from regional PA network managers since the early 1990s (EUROPARC-España, 1995). This collaboration is likely to have helped to shape common views and interests and positively 'contaminated' scientists with managers' perceptions of items of conservation importance and vice versa. Despite these helpful recurring initiatives, there is still no standardised PA monitoring and assessment system in the country and most PAs in Spain are not yet monitored or assessed, with the exception of national parks and some nature parks (Rodríguez-Rodríguez et al., 2015). There are a number of terrestrial PA monitoring and assessment systems in Spain that could be used as a basis for a common system: Mallarach (2008), Rodríguez-Rodríguez and MartínezVega (2012), MAGRAMA (2014). In the marine realm, Tempesta and Otero (2013) developed a useful set of 'protected area management effectiveness' (PAME) and 'ecological condition' indicators for Mediterranean marine PAs. However there seems to lack enough political commitment to implement any of these systems or to develop new ones in Spain (Rodríguez-Rodríguez et al., 2015).

Of the 7 most highly ranked indicators by managers and scientists, only 'Population trends of endangered species or subspecies' was included among the most highly ranked indicators in the original SIAPA. The manager of the ARM also rated 'Appropriateness of protection legislation' and 'Fragmentation' the highest. However, he rated the remaining 6 most highly ranked indicators by managers and scientists as well as 'Sanctioning procedures' and 'Area provided for the protected area by municipalities with local Agenda 21', both lowly rated by managers, as 'moderately important', and instead rated 'Land ownership', 'Number of visitors', 'Existence of updated planning documents' and 'Existence of updated management documents', all moderately rated by managers, among the most important indicators in the ARM. These differences may indicate the 'singularity' of the small urban region of Madrid (Hewittand Escobar, 2011) with a high tourist and population pressure onits PAs (Rodríguez-Rodríguez, 2008, 2012a) and a higher need for planning, enforcement and local sustainability.

\subsection{Open responses}

A number of new indicators were proposed by both scientists and managers, although few of them had some degree of agreement. One of these indicators was 'Change in extent of focal habitats' that is driven by European legal requirements: The Habitats Directive (EU, 1992). The inclusion of such an indicator is thus a must in PA monitoring and assessment systems for European Pas included in the Natura 2000 Network.

Lack of awareness of the technicalities of the SIAPA brought about several remarks and questions on definitions (e.g. 'Appropriateness of protection legislation'), justification of importance (e.g. 'Existence of updated documents on social and economic development'), measurements and interpretations of indicators (e.g. 'Land use changes') that had been clearly specified in the preparation materials sent prior to the workshop. Lack of time seemed to have been the main hindrance for a previous closer review of the workshop materials. Insufficient knowledge of the specificities of the SIAPA also led to some 'new' indicators being proposed that duplicated or were closely related to some of the existing indicators in the SIAPA (e.g. 'Change in local population' vs 'Local population density' or 'Connectivity of the PA' vs 'Isolation of the PA'). Consideration should thus be paid to devoting some time to clearly specifying a precise working frame in terms of names, definitions, assumptions, measurements, scales, etc. at the beginning of such participative exercises in order to reduce personal biases due to different interpretations of the topics or concepts being assessed, as suggested elsewhere (Cook et al., 2014).

\subsection{Original SIAPA model comparison}

The slightly higher ratings of the SM compared to the CM by PA network managers and scientists provide little evidence to validate the higher salience of the SM in a Spanish context, in contrast to what was suggested previously (Rodríguez-Rodríguez and Martínez-Vega, 2012). A new, highly agreed and salient simplified system can, however, be proposed from the most highly ranked indicators by both priority groups attending the workshop. 
Table 3

Coefficients of variation (CV.mSIAPA) and mean values of the SIAPA's partial indexes by PA network managers (M.mSIAPA; $n=11$ ), scientists (M.sSIAPA; $n=3$ ), original SIAPA stakeholders (M.oSIAPA; $n=6$ ), and the PA network manager of the Autonomous Region of Madrid (M.armSIAPA; $n=1$ ) on a 1-5 point scale.

\begin{tabular}{llllll}
\multicolumn{5}{l}{ stakeholders (M.oSIAPA; $\mathrm{n}=6$ ), and the PA network manager of the Autonomous Region of Madrid (M.armSIAPA; $\mathrm{n}=1$ ) on a 1-5 point scale. } \\
\hline Index & CV.mSIAPA & M.mSIAPA & M.sSIAPA & M.oSIAPA & M.armSIAPA \\
\hline State of conservation & 5.86 & 4.91 & 3.33 & 4.33 & 5.00 \\
Management & 22.52 & 4.27 & 4.33 & 3.83 & 3.00 \\
Planning & 23.84 & 4.00 & 3.33 & 3.50 & 4.00 \\
Social perception and valuation & 25.78 & 3.45 & 2.33 & 3.50 & 3.00 \\
Threats to conservation & 26.11 & 4.00 & 3.67 & 4.33 & 4.00 \\
Social and economic framework & 42.62 & 2.91 & 2.00 & 4.21 & 4.00
\end{tabular}

existence of differences in PA management between the

\subsection{Agreement on the importance of the SIAPA indicators and indexes}

The strong agreement in the ratings of the SIAPA indicators (very statistically significant) and indexes (nonsignificant) between PA network managers and scientists advocate that an agreed, standardised PA assessment system for the whole country can be proposed. This standardised system could use new weights to integrate those indicators into partial indexes according to these groups' mean ratings of the SIAPA indexes. However, representation of scientific organisations within this proposed system is limited and could be improved by incorporating ratings by other relevant scientific institutions from Spain. Also, greater consideration to scientific priorities could be given, for instance, by including other highly rated indicators by scientists that were not so highly rated by managers.

The weak associations of the ratings of the SIAPA indicators between Spanish PA network managers and the original SIAPA stakeholders, and between scientists (statistically significant in this case) and the original SIAPA stakeholders suggest improvable national representation by the original set of SIAPA stakeholders. Insufficient stakeholder representation is likely to have influenced SIAPA's limited salience and uptake by endusers in Spain (Rodríguez-Rodríguez et al., 2015). The fact that the SIAPA was originally developed for use in the ARM and that the only PA manager's input to the selection and rating of indicators and indexes of the SIAPA was the PA network manager of the ARM probably determined its limited salience outside the ARM.

The very weak association in the ratings of the SIAPA indicators by PA network managers and the PA network manager of the ARM seems to further add to the suggestions made at the work-shop and in previous studies (Hewitt and Escobar, 2011) regarding the 'uniqueness' of the ARM in the Spanish context, leading to singular biodiversity management priorities. Both manager groups agreed very strongly and significantly, however, in the ratings of the SIAPA partial indexes, suggesting that they both agree in the most important factors to influence the effectiveness of PAs. For both of them, the 'State of conservation' is the most determinant factor of PA effectiveness. Nevertheless, there are also some differences in index ratings between these two groups, as the PA network manager of the ARM also rated 'Management' the highest, whereas for the rest of PA network managers 'Management' is secondary for PA effectiveness. Even though our results suggest the
ARM and the rest of the Spanish regions, these differences may also be due to the personal preferences or bias by the only assessor of the ARM, as every surveyee is likely to introduce an element of intrinsic uncertainty in any stakeholder analysis (Pomeroy and Douvere,2008).

There was a strong association (non-significant) in the ratings of the SIAPA indexes between the other three groups: PA network managers, scientists and original SIAPA stakeholders. However, the most important index for PA network managers was, by far, the 'State of conservation', whereas scientists placed the highest importance on 'Management'. PA network managers and scientists however agreed that the categories 'Social and economic context' and 'Social perception and valuation' were the least important $\left(6^{\text {th }}\right.$ and 5th place respectively, according to their means) for assessing the overall effectiveness of PAs. Paradoxically, 'Social and Economic Context' was the index for which PA network managers suggested to include more new indicators (appendix $\mathrm{C}$ in the supplementary material). These findings contrast with a previous study that showed that the indexes 'State of conservation' and 'Social perception and valuation' were the only partial indexes of the SIAPA strongly and significantly correlated with the effectiveness of Pas (Rodríguez-Rodríguez and Martínez-Vega, 2013a). Other studies have also suggested the importance of local stakeholders' perceptions and involvement for the success of conservation actions in Europe (Nolte et al., 2010) and in Spain (Rodríguez-Rodríguez,2012b). This finding suggests that science could be ahead of management in following an ecosystem approach (CBD, 2004) to PA monitoring and assessment in Spain.

\subsection{Linking management actions to conservation outcomes}

The fact that PA network managers perceived the 'State of conservation' as the most important factor to determine PA effectiveness instead of 'Management', which was preferred by scientists, raises some interesting questions: is PA effectiveness driven (and thus should be assessed) by the effectiveness of its management, or by its conservation outcomes? Is PAME a useful predictor of PA (conservation) effectiveness? Carranza et al. (2014) recently added to the debate and found no relation between PAME scores and conservation outcomes (measured by avoided land-use con-version) using RAPPAM (Ervin, 2003) in Brazil.

In the absence of further evidence and following the precautionary principle, its seems reasonable to assess PA 
effectiveness primarily on conservation outcomes (i.e. state of conservation of (sub)species, habitats, landscapes and ecological processes), rather than on its management proxies when it is feasible. In the face of continuing global biodiversity loss (Butchart et al., 2010), good conservation outcomes are more important than good management results in terms of planning, inputs, processes and outputs, following the IUCN's PAME framework terminology (Hockings et al.,2006). Evidence is needed, however, to be able to attribute management efforts to conservation outcomes. This link is unlikely to be established without adequate controls (Addison, 2011). Both PA network managers and scientists highlighted the need to compare the results of some indicators (e.g. indicators in the 'State of conservation' index) inside and outside PAs, as well as between management zones.

PAMEs based on managers' opinions were found not to be accurate (Carranza et al., 2014) or precise enough (Cook et al., 2014). Other more objective, data-driven and resource-intensive assessment systems, like the PEIN evaluation (Mallarach, 2008) or the SIAPA (RodríguezRodríguez and Martínez-Vega, 2012) still face attribution problems as no controls outside PAs were included to compare results from inside PAs. Thus, they are just able to indiscriminately assume the effects of socioeconomic contexts, regulations, management actions or others on conservation outcomes. Before-After-Control-Impact designs (Smith, 2002) where the 'impact' represents legal designation or active management of the PA can provide an adequate methodological framework to link management actions and conservation outcomes more soundly and objectively (Addison, 2011). For this statistical approach to PAME to be implemented, regular and consistent time-series of ecological, social and/or economic monitoring data (depending on each PAs' conservation and management objectives) are needed. Issues regarding the selection of adequate control sites in terms of similarity with PAs are foreseeable, especially in highly humanised contexts like Europe. Similarly, the feasibility of extending monitoring programmes outside PAs and to highly mobile species (e.g. birds, large mammals) remains questionable in what appears to be chronically underfunded PAs (Chape et al., 2008; Leverington et al.,2010a). However, we think that steps in that direction should be made wherever possible in order to assess the real contribution of legal, managerial and other contextual factors to the conservation of protected features, as well as to discriminate good and poor management outcomes and practices.

\section{Conclusions}

This study suggests that a common, agreed and salient PA evaluation system based on the improved version of the SIAPA shown here could be easily and cost-effectively implemented in Spain. This standardised system could be based on the 7 SIAPA most highly ranked indicators by our sample of PA network managers and scientists plus the new, highly agreed indicator 'Change in extent of focal habitats', and could be complemented by site-specific indicators to account for regional or local characteristics and/or by some additional priority indicators for scientists. A wider representation of national scientific organisations would be advisable in order to increase the representation of this other priority group in the proposed system.

The development of PA evaluation systems, especially the indicator and index-selection and rating phases, should include a wide range of stakeholders, chiefly PA managers, PA network managers and decision-makers as end-users, to maximise the systems' legitimacy, credibility, salience and ultimate implementation (Cooket al., 2013). Nevertheless, no matter how sound, inclusive or salient a scientific output is if there is insufficient political commitment or will to implement it (Rodríguez-Rodríguez et al., 2015). It is thus now up to the Spanish conservation authorities to make use of this new tool with remarkable scientific and managerial consensus to monitor and assess the country's rich biodiversity according to international (CBD, 2010a,b), European (EU, 1992) and national (Spanish Government, 2007) requirements.

The methods, results and suggestions of this study will help researchers to better focus on the evaluation needs of PA managers when designing monitoring and evaluation systems, especially in Euro-Mediterranean contexts, as well as to come closer to meeting the CBD's recommendations and targets.

\section{Acknowledgements}

We would like to thank the BBVA Foundation for its logistical and financial support for convening the 1st National Workshop on Protected Area Effectiveness Evaluation (SIAPA). We would also like to acknowledge and thank all the participants in the workshop for their useful contributions and the anonymous reviewers for their helpful comments on an earlier version of this manuscript.

\section{Appendix A. Supplementary data}

Supplementary data associated with this article can be found, in the online version, at http://dx.doi.org/10.1016/j. ecolind.2016.01.011.

\section{References}

Addison, P., 2011. A global review of long-term Marine Protected Area monitoring programmes: The application of a good framework to marine biological monitoring. A report prepared for the Joint Nature Conservation Committee. JNCC, Peterborough, http://jncc.defra.gov.uk/pdf/jncc 455Vol1 Vol2\%20combined_web.pdf (retrieved 16.07.14). 
Bonett, D.G., 2006. Confidence interval for a coefficient of quartile variation. Comput. Stat. Data Anal. 50, 2953-2957.

Butchart, S.H.M., Walpole, M., Collen, B., van Strien, A., Scharlermann, J.P.W., Almond, R.E.A., Baillie, J.E.A., Bomhard, B., et al., 2010. Global biodiversity: indicators of recent declines. Science 328 (5982), 1164-1168.

Carranza, T., Manica, A., Kapos, V., Balmford, A., 2014. Mismatches between conservation outcomes and management evaluation in protected areas: a case study in the Brazilian Cerrado. Biol. Conserv 173, 10-16.

CBD, Convention on Biological Diversity, 2004. The Ecosystem Approach. Secretariat of the Convention on Biological Diversity, Montreal, https://www.cbd.int/doc/publications/eatext-en.pdf (retrieved 29.08.14).

CBD, Convention on Biological Diversity, http://www.cbd.int/decision/cop/?id=12297 (retrieved 29.08.14) 2010a. COP 10 Decision X/31. Protected Areas. United Nations Environment Programme, Nairobi.

CBD, Convention on Biological Diversity, 2010b. Aichi Biodiversity Targets. United Nations Environment Programme, Nairobi, http://www.cbd.int/sp/targets/default. shtml (retrieved 29.08.14).

CBD, Convention on Biological Diversity, 2014. Information. Country profiles. Spain. United Nations Environment Programme, Nairobi, http://www.cbd.int/countries/? country=es (retrieved 15.08.14).

Chape, S., Spalding, M., Jenkins, M. (Eds.), 2008. The World's Protected Areas. Status, Values and Prospects in the 21st Century. University of California Press, Berkeley, Prepared by the UNEP World Conservation Monitoring Centre.

Coad, L., Leverington, F., Burgess, N.D., Cuadros, I.C., Geldmann, J., Marthews, T.R.,Mee, J., Nolte, C., et al., 2013. Progress towards the CBD protected area management effectiveness targets. Parks 19, 1.

Cook, C.N., Carter, R.W., Fuller, R.A., Hockings, M., 2012. Managers consider multiple lines of evidence important for biodiversity management decisions. J. Environ. Manag. 113, 341-346.

Cook, C.N., Mascia, M.B., Schwartz, M.W., Possingham, H.P., Fuller, R.A., 2013. Achieving conservation science that bridges the knowledge-action boundary. Conserv. Biol. 27, 669-678.

Cook, C.N., Carter, R.W., Hockings, M., 2014. Measuring the accuracy of management effectiveness evaluations of protected areas. J. Environ. Manag. 139, 164-171.

Dudley, N. (Ed.), 2008. Guidelines for Applying Protected Area Management Cate-gories. IUCN, Gland, Switzerland.

Edgar, G.J., Stuart-Smith, R.D., Willis, T.J., Kininmonth, S., Baker, S.C., Banks, S., Barrett,N.S., Becerro, M.A., et al., 2014. Global conservation outcomes depend on marine protected areas with five key features. Nature 506 (7487), 216-220.

EEA, European Environment Agency, 2006. Data and maps. Datasets. Biogeographical Regions, http://www.eea.europa.eu/data-and-aps/data/biogeographicalregions-europe-2005 (retrieved 13.09.14).

Ervin, J., 2003. Rapid Assessment and Prioritization of Protected Areas Management(RAPPAM) Methodology. WWF, Gland.

Europarc-España, 1995. Protected Areas of Spain at the Beginning of the XXI Century. Europarc-España, Madrid, Spain (in Spanish).

EU, European Union, 1992. Habitats Directive (amended version),

http://eurlex.europa.eu/LexUriServ/LexUriServ.do?uri=CONSLEG:19 92L0043:20070101:EN:PDF (retrieved 16.08.14).

Europa Press, 2013. Expertos en gestión medioambiental estudiarán cómo evaluar la eficacia de las áreas protegidas españolas. Europa Press, Madrid, Spain (in Spanish) http://www.europapress.es/epsocial/fundaciones/noticiaexpertos-gestion-medioambiental-estudiaran-evaluareficacia-areas-protegidas-espanolas-20130510145507.htm (retrieved 25.09.14).

Euser, A.M., Dekker, F.W., le Cessie, S., 2008. A practical approach to Bland-Altman plots and variation coefficients for log transformed variables. J. Clin. Epidemiol.61 (10), 978982

Hewitt, R., Escobar, F., 2011. The territorial dynamics of fastgrowing regions: unsustainable land use change and future policy challenges in Madrid, Spain. Appl. Geogr. 31, 650667.

Hockings, M., Stolton, S., Dudley, N., 2000. Evaluating Effectiveness: a Framework for Assessing the Management of Protected Areas. IUCN, Gland and Cambridge.

Hockings, M., Stolton, S., Dudley, N., 2006. Evaluating Effectiveness: A Framework for Assessing the Management of Protected Areas, 2nd ed. IUCN, Gland and Cambridge.

Leverington, F., Lemos, K., Courrau, J., Pavese, H., Nolte, C., Marr, M., Coad, L., Bur-guess, N., et al., 2010a. Management Effectiveness Evaluation in Protected Areas- A Global Study. University of Queensland, Brisbane.

Leverington, F., Lemos, K., Pavese, H., Lisle, A., Hockings, M., 2010b. A global analysis of protected area managemen effectiveness. Environ. Manag. 46, 685-698.

MAGRAMA, Ministerio de Agricultura, Alimentación y Medio Ambiente, 2012.Second report on the situation of the National Park Network (2007-2010).I State of the Network (in Spanish) http://www.magrama.gob.es/es/red-parquesnacionales/la-red/gestion/Informe-Red2 tcm7-281101.pdf (retrieved30.08.14).

MAGRAMA, Ministerio de Agricultura, Alimentación y Medio Ambiente, 2014.National Park Network. Monitoring and Assessment (in Spanish) http://www.magrama.gob.es/es/redparques-nacionales/plan-seguimiento-evaluacion/\#(retrieved 30.08.14).

MAGRAMA, Ministerio de Agricultura, Alimentación y Medio Ambiente, 2015.Biodiversity. Protected areas. Natura 2000 Network in Spain (in Spanish) http://www. magrama. gob.es/es/biodiversidad/temas/espaciosprotegidos/red-natura-2000/rn espana.aspx (retrieved 17.02.15).

Mallarach, J.M., 2008. Protected in Fact or by Law? First Assessment of the Protected Area System of Catalonia. Institució Catalana d'Història Natural, Barcelona (in Catalan) http://ichn.iec.cat/Avaluacio Espais.htm (retrieved 30.08.14).

Múgica, M., Gómez-Limón (coord), J., 2002. Action Plan for the Protected Areas ofSpain. Fundación Fernando González Bernáldez, Madrid (in Spanish).

Múgica, M., Martínez, C., Gómez-Limón, J., Puertas, J., Atauri, J.A., 2012. 2011 Year-book on the Status of Protected Areas in Spain. Fundación Fernando González Bernáldez, Madrid (in Spanish)

Nolte, C., Leverington, F., Kettner, A., Marr, M., Nielsen, G. Bomhard, B., Stolton, S., Stoll-Kleemann, S., et al., 2010. Protected Area Management Effectiveness Assessments in Europe. A Review of Application, Methods and Results. University of Greifswald, Greifswald, http://d2ouvy59p0dg6k.cloudfront.net/downloads/mett2 final version july 2007.pdf (retrieved 11.12.15).

Pomeroy, R., Douvere, F., 2008. The engagement of stakeholders in the marine spatial planning process. Mar. Policy 32, 816822.

Reed, M.S., 2008. Stakeholder participation for environmental management: a literature review. Biol. Conserv. 141, $2417-$ 2431 . 
Rodríguez-Rodríguez, D., 2008. Main Threats to the Protected Areas of the Autonomous Region of Madrid. Editorial Complutense, Madrid (in Spanish).

Rodríguez-Rodríguez, D., 2012a. Integrated networks. A territorial planning proposal for biodiversity conservation in urban, densely populated regions. The case of the Autonomous Region of Madrid, Spain. J. Environ. Plann. Manag. 55,667-683.

Rodríguez-Rodríguez, D., 2012b. Perception, use and valuation of protected areas by local populations in an economic crisis context. Environ. Conserv. 39,162-171.

Rodríguez-Rodríguez, D., Martínez-Vega, J., 2012. Proposal of a system for the integrated and comparative assessment of protected areas. Ecol. Indic. 23,566-572

Rodríguez-Rodríguez, D., Martínez-Vega, J., 2013a. Results of the implementation of the System for the Integrated Assessment of Protected Areas (SIAPA) to the protected areas of the Autonomous Region of Madrid (Spain). Ecol. Indic. 34,210-220.

Rodríguez-Rodríguez, D., Martínez-Vega, J., 2013b. Protected area effectiveness assessment. The System for the Integrated Assessment of protected Areas(SIAPA). Results of the first integrated assessment of the protected areas of the Autonomous Region of Madrid. BBVA Foundation, Madrid (in Span-ish) http://www.fbbva.es/TLFU/tlfu/esp/publicaciones/informes/fi chainforme/index.jsp?codigo=722 (retrieved 15.09.14).
Rodríguez-Rodríguez, D., Martínez-Vega, J., Tempesta, M. Otero-Villanueva, M.M.,2015. Limited uptake of protected area evaluation systems among managersand decision-makers in Spain and the Mediterranean Sea. Environ. Conserv. 42(3), 237-245.

Smith, E.P., 2002. BACI design. In: El-Shaarawi, A.H., Piegorsch, W.W. (Eds.),Encyclopedia of Environmetrics, vol 1. John Wiley \& Sons, Chichester,pp. 141-148, http://people.stat.sfu.ca/ cschwarz/Stat-

650/Notes/Handouts.readings/smith-2002-EES-baci.pdf (retrieved 30.08.14).

Spanish Government, 2007. Law 42/2007, of 13th of December, on Natural Patri-mony and Biodiversity. Agencia Estatal Boletín Oficial del Estado, Madrid (in Spanish) https://www.boe.es/buscar/act.php?id=BOE-A-2007-21490 (retrieved13.09.14).

Stolton, S., Hockings, M., Dudley, N., MacKinnon, K., Whitten, T., Leverington, F., 2007. Reporting Progress in Protected Areas. A Site Level Manage-ment Effectiveness Tracking Tool, 2nd ed. World Bank/WWF Forest Alliance and WWF Gland, http://assets.panda.org/downloads/mett2 final version july2007.pdf (retrieved 11.02.15).

Tempesta, M., Otero, M., 2013. Guide for Quick Evaluation of Management in Mediterranean MPAs. World Wildlife FundItaly and IUCN, Centre for Mediterranean Cooperation, Rome, Málaga, https://portals.iucn.org/library/efiles/edocs/ 2013-018.pdf (retrieved 25.09.14). 